\title{
MULTILINGUALISM, INTERCOMPREHENSION AND INCLUSION: THE LECTURIO + PROJECT AND THE DYSLEXIC STUDENT
}

\author{
Stefania Pinnelli, Andrea Fiorucci, Clarissa Sorrentino, \& Marina De Nunzio \\ Department of History, Society and Human Studies, University of Salento (Italy)
}

\begin{abstract}
In the Common European Framework of Reference for Languages: Learning, Teaching, Assessment (CEFR, Cambridge University Press, ISBN: HB 0521803136 - PB 0521005310 www.uk.cambridge.org/elt), it is emphasized that languages should not be considered as compartments ponds to be faced and learned in isolation, and that by "plurilingualism" we mean the integration of different linguistic repertoires which do not necessarily imply complete mastering of all abilities.

Lecturio + is an Erasmus + project funded by the European Community for a partnership of public and private bodies. It develops along two lines of action: production and experimentation of learning paths of Romance languages on the model of linguistic inter-understanding and planning and implementation of an international summer school. Regarding the first action Lecturio + provides for the creation of a multilingual narrative tool intended for 8-year-old children of 3 European countries that guarantees attention also to dyslexic students. Moving from the scientific references on the difficulties in learning L2 for dyslexic students, the working group of the CNTHI of Unisalento, has been responsible for the inclusive design of the teaching tool, it is the book version and the Kamishibai version of a story titled "Thomas and the watermelon ", its adaptation to make it accessible and the methods of fruition and evaluation also through the digital version. This is a text structured according to the criteria of inclusive teaching that is proposed in schools in the partner countries of the project and translated into 14 languages. The purpose of the grant is to stimulate the learning of L2 through immersive experiences. The CNTHI working group has also organized two tools for the exploration of beliefs and attitudes towards the learning of a foreign language of teachers and students of the 4 primary school classes where the tools comes tried out. The aim is to recognize the preliminary components of a positive approach to the language.

Partners of The Lecturio + Project Are: Association Internationale Pour La Promotion de L'intercompréhension À Distance - France; Lycée Le Mas Blanc - France: Fédération Régionale des Maisons Familiales Rurales de Midi-Pyrénées - France: University of Salento - Italy; Universitat de Barcelona - Spain; Universite de Corse Pascal Paoli - France; Universitat des Saarlandes - Deutschland; University of the Studies Roma Tre - Italy.
\end{abstract}

Keywords: Intercomprehension, dyslexic students, inclusive didactic tool.

\section{What is linguistic intercomprehension?}

The term "intercomprehension" refers to the phenomenon that occurs when two people communicate successfully with each other by talking to each other in their own language. Inter-comprehension teaching is not an alternative to learning all the linguistic skills of a foreign language but represents an approach aimed at developing linguistic awareness, which aims at the enhancement of all languages, in perfect line with the Common European Framework of Reference for Languages (CEFR).

In fact, the CEFR emphasizes, on several occasions, that languages must not be considered as separate compartments to be faced and learned in isolation, and that "multilingualism" means the integration of different linguistic repertoires that do not necessarily imply complete mastery of all skills.

"The aim of language education is profoundly modified. It is no longer seen as simply to achieve 'mastery' of one or two languages, each taken in isolation, with the 'ideal native speaker' ... Instead, the aim is to develop a linguistic repertory, in which all linguistic abilities have a place."(QCER, 2001).

The intercomprehension allows the concrete realization of a plurilingual and multicultural European context, supporting diversity as an alternative to a single language of communication.

From the point of view of linguistic competences, the intercomprehension starts from the exploitation of the closeness and affinity of languages that belong to the same linguistic group, such as for 
example the Romance languages, have numerous elements (lexical, phonological, morphological, syntactic) to which we add the discursive, textual or cultural clues related to a specific linguistic-cultural community

From the point of view of operational skills, the intercomprehension is based on the partial competences in which the competence of understanding is separated from that of production, the similarities between languages are exploited, the awareness of what each speaker already knows about the nature of the language, on the communication systems develops and on human interaction to accelerate mutual understanding processes and mobilize relational cognitive and emotional skills to build a common understanding plan. In the last decade of the last century, some European universities have begun to develop materials aimed at developing language learning according to the principles of intercomprehension. One of these teams led by Claire Blanche-Benveniste gave rise to EuRom4 (CEFR, cit).

\section{Intercomprehension and inclusive teaching}

In the educational field with the Salamanca Declaration (1994), attention was paid to every form of diversity, understood as a value in itself and to its recognition in a school for all, indicating the accessibility and participation of all children, regardless of disadvantaged situations, to common training paths. Inclusion is therefore the ability to provide a framework within which pupils - regardless of ability, gender, language, ethnic or cultural origin - can be equally valued, is a widespread and stable guarantee of participation and promotion of potential in terms of learning and development. "Inclusion moves from the recognition of differences between pupils" (Booth, Ainscow, 2008 p. 111). Inclusive educational contexts may be more appropriate even in situations of deficit and disability, as they are more designed and organized to reduce obstacles and to facilitate flexibility and personalization.

Learning the foreign language constitutes, in the educational training path, one of the most significant goals that contribute to completing the framework of key competences and that contribute to the formation of an intercultural and citizenship education. For this reason it is necessary to activate any form of intervention aimed at promoting the participation and inclusion of the students, removing educational or linguistic barriers that hinder training and designing accessible learning environments. These indications become even more important if we think of students with learning disabilities or dyslexia. "Dyslexia is a specific learning disability that is neurobiological in origin. It is characterized by difficulties with accurate and/or fluent word recognition and by poor spelling and decoding abilities. These difficulties typically result from a deficit in the phonological component of language that is often unexpected in relation to other cognitive abilities and the provision of effective classroom instruction. Secondary consequences may include problems in reading comprehension and reduced reading experience that can impede growth of vocabulary and background knowledge." (Definition Adopted by the IDA Board of Directors, Nov. 12, 2002.). Even the person who has very much compensated for the problem of dyslexia with early rehabilitative interventions, that lead him to have performances similar to those of the normolector, with regard to word recognition continues to always have a phonological deficit that makes the reading less automatic and therefore slow and poorly flowing (Shaywitz., et alii 1999).

The dyslexic student presents many difficulties in the encounter with the foreign language both for the written part and for the spoken part. In the listening comprehension phase, it can be very tiring to segment the meaning units into the communicative flow, and will be able to perceive a higher speech speed than the companions. In the written comprehension he will encounter difficulties in deciphering the graphic units, in the association between signifiers and meanings and in the speed of reading. (Daloiso, 2009).

\section{The Lecturio + project}

In the perspective of favoring the learning of the foreign language in the dyslexic child, but above all in the perspective of building a positive and possibilist attitude in students with learning difficulties or disabilities, the Lecturio + project was designed and implemented.Lecturio + is an Erasmus + project funded by the European Community for a partnership of public and private bodies. It develops along two lines of action: production and experimentation of learning paths of Romance languages on the model of linguistic inter-understanding and planning and implementation of an international summer school. Regarding the first action Lecturio + provides for the creation of a multilingual narrative tool intended for 8-year-old children of 3 European countries that guarantees attention also to dyslexic students. The Lecturio + project was aimed at creating multilingual educational resources. In particular in this article we will talk about a narrative product called "Tommaso e l'anguria" a simple story for children, proposed in 14 different languages and with different modalities. As part of the Lecturio + project, the CNTHI of the University of Salento oversaw the adaptation of the text and images of the educational tool built for the project: the book Tommaso E L 'Anguria and its kamishibai version. The process of adaptation and revision made to the 
identified cultural product (a story entitled "Thomas and the watermelon") has taken into account the pedagogical principles of the inclusive model in teaching design (Index 2012 and ICF 2001), and taking into account the characteristics functioning of the pupil with DSA and, in particular, of the dyslexic student especially as regards executive functions. The text of the story has been revised both for the lexical and graphic elements. The text-image consistency, the legibility of the text, the graphic choices of presentation of the textual part and images, the chromatic choices and everything else necessary to support the pupils in the comprehension by listening and reading the history was taken care of. The typical critical points of the dyslexic student concern the thresholds of attention, in particular the control of the interference and the management of working memory (Benso 2004), which are associated with the problems of visual interference and overcrowding (Rome High Health Institute 2010).

Figures 1, 2, 3 represent some of the steps in the adaptation of a Book table. The text consists of 14 tables. The adaptation work was carried out on each one. The principles of adaptation are illustrated in an educational video broduced the CNTHI. (https://drive.google.com/drive/folders/17ueMUxTv2iOv0zAqD8r6MlLSBfsZPh-B).

Figure 1. Original version of the book's page.

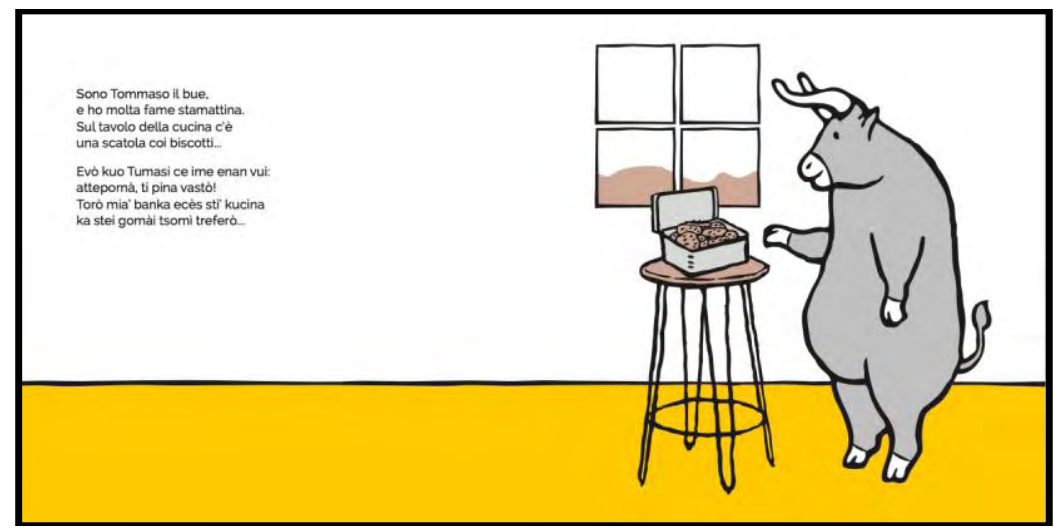

Figure 2. First Adaptation.

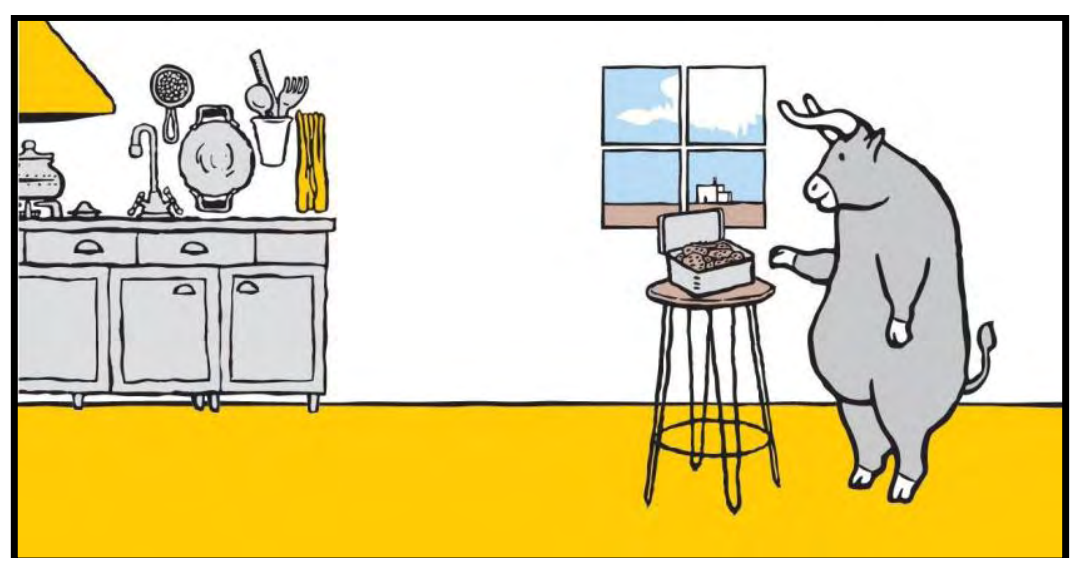

Figure 3. Final Adaptation.

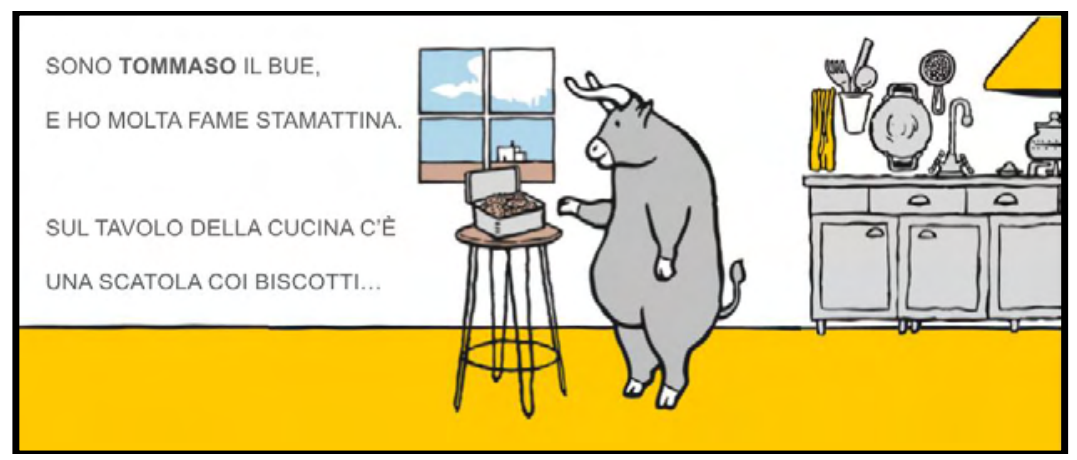


The revision action was made to reduce the perceptual gap, the effect of visual crowding, the ambiguity of words and images. Use of the font, of the Uppercase, of the simplification, of the appropriate line spacing. In addition, all the graphic styles have been revised to increase the readability of the text and the understanding of the story. Both the adaptation of the story and the adaptation of the didactic activity carried out with history have been guided by the idea of producing a unique project for the whole class in response to the culture of inclusion that organizes and designs educational initiatives that do not exclude anyone. The story in book and kamishibai format was tested in March, on 4 third primary classes in a school in the province of Lecce. 78 children are involved, one with a dyslexia certification and seven with non-certified learning difficulties, but detected by the teachers. Tommaso's story in Italy will be tested in all foreign languages, while in the group of 78 children in French and Spanish. Both languages are not a subject of school study, in fact in all four classes children study English as L2. The story is read in the foreign language by the recorded voice of a native speaker, the reading takes place at a slow pace, articulating the most important keywords and is accompanied by the kamishibai tables, without text only images. The slow and punctual reading responds to the needs of a slow phonological processing typical of the dyslexic student. The reading is proposed twice. In the pretest phase it was realized that, unlike the classical reading of the kamishibai in which the streak anticipates the illustrated table, in this case the story read must correspond to an illustrated table that is shown to children, to reduce the difficulty of managing a double attention task and not to overload short-term memory. Later the children participate in a series of phonological didactic games to explore the similarities of new words, meanings and differences. The purpose of the educational activities is to make people reflect on the active listening techniques put in place and on how to manage the metacognitive strategies to better understand the content of the story.

Figure 4. The experimentation in the classroom.
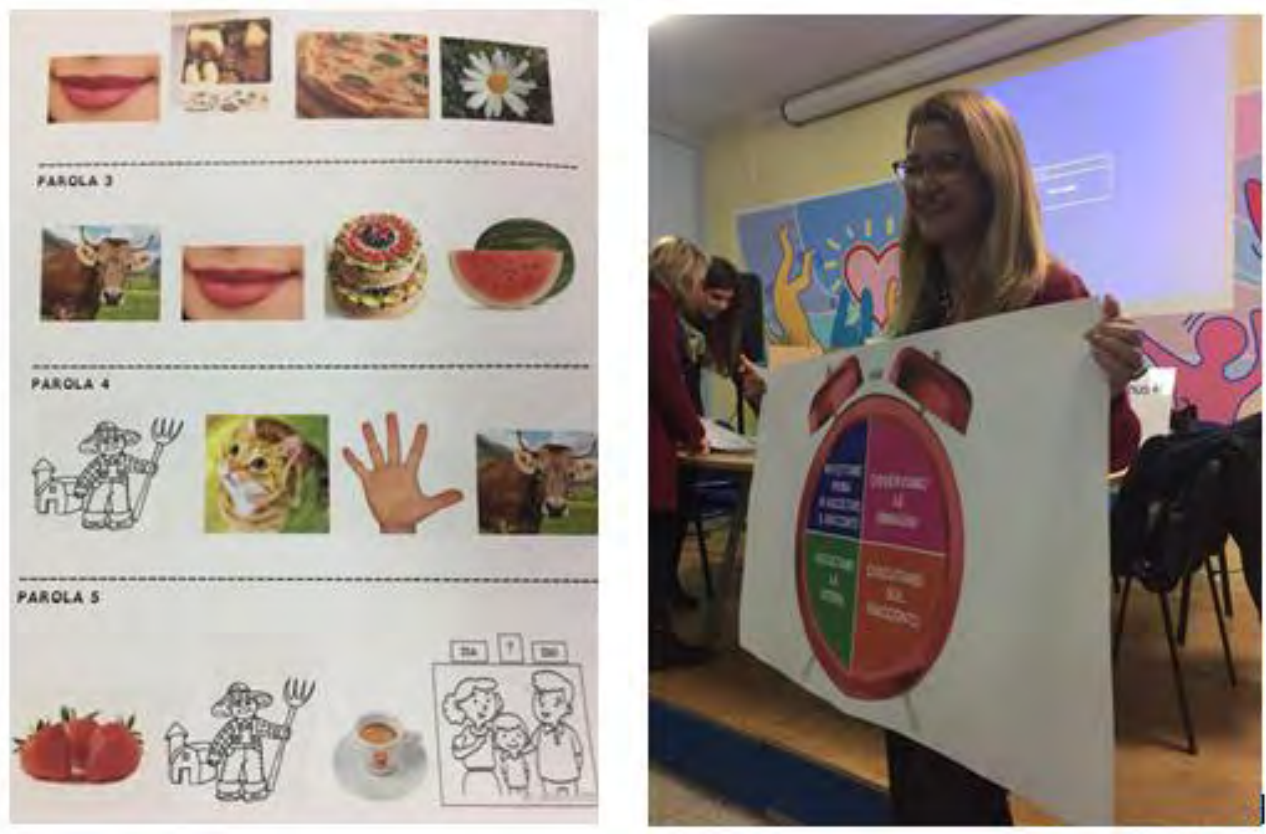

Before the workshop activity with the kamishibai, the children completed a questionnaire of 10 questions to detect their attitude towards foreign language learning and the idea they have regarding the usefulness of knowledge of other languages. For children in reading difficulties, the questionnaire will be proposed in the form of an interview. The hypothesis is that there is a general resistance to language learning influenced by the scholastic approach to the subjects and that in children in difficulty this resistance is significantly higher than in the rest of the group. In response to this problem an inclusive and interactive approach to languages is proposed that can lead all students towards good results and not only those who have specific talents in language learning, because the aptitude for language learning, as a factor of individual difference or personal predisposition that facilitates learning itself is not a determinant in the absolute sense of success in learning but rather an element conditioning the speed of the process involved and the level of achievable results (Gardner and MacIntyre 1992). 


\section{References}

Benso F. (2004), Neuropsicologia dell'attenzione. Teoria e trattamento nei disturbi specifici di apprendimento. Pisa: Ed. Del Cerro.

Booth T, Ainscow M. (2008 and 2014), Nuovo Index per l'inclusione. Roma: Carocci.

Consesus Conference (2010). Linee guida Istituto Superiore di Sanità Roma.

Daloiso M. (2009), La dislessia evolutiva: un quadro linguistico, psicolinguistico e glottodidattico, Studi di Glottodidattica, 3, 25-43.

Gardner R., MacIntyre P. (1992). A student's contributions to second-language learning. Part I: Cognitive variables, Language Teaching, 25, 211-220.

IDA Board of Directors, Nov. 12, 2002

QCER, European Council (2001). The Common European Framework of Reference for Languages: Learning, teaching, assessment (CEFR), Cambridge University Press.

Shaywitz S.E., Fletcher J.M., Holahan H.M., Schneider A.E., Marchione K.E., Stuebing K.K., Francis D.J., Pugh K.R. e Shaywitz B.A. (1999), Persistence of dyslexia: The Connecticut Longitudinal Study at adolescence, «Pediatrics», 104, 1351-1359.

UNESCO (1994). The Salamanca Statement and Frame work for Action on Special Needs Education, 7-10 Giugno 1994, Paris.

WHO (OMS) (2001), International classification of functioning, disability and health: ICF. World Health Organization, Geneva. 